\title{
Who is the best haploidentical donor for acquired severe aplastic anemia? Experience from a multicenter study
}

\author{
Lan-Ping $\mathrm{Xu}^{1 \dagger}$, Shun-Qing Wang ${ }^{2 \dagger}$, Yan-Ru Ma', Su-Jun Gao ${ }^{3}$, Yi-Fei Cheng ${ }^{1}$, Yuan-Yuan Zhang ${ }^{1}$, Wen-Jian Mo ${ }^{2}$, \\ Xiao-Dong Mo ${ }^{1}$, Yu-Ping Zhang ${ }^{2}$, Chen-Hua Yan' ${ }^{1}$, Yu-Hong Chen ${ }^{1}$, Ming Zhou ${ }^{2}$, Yu Wang ${ }^{1}$, Xiao-Hui Zhang ${ }^{1}$, \\ Kai-Yan Liu ${ }^{1}$ and Xiao-Jun Huang ${ }^{1,4,5^{*}}$ (D)
}

\begin{abstract}
Background: Haploidentical transplantation has been proposed as an effective treatment for severe aplastic anemia (SAA). The majority of patients have more than one HLA-haploidentical donor. Herein, we compared the outcomes between different donor-recipient relationships for optimal haploidentical donor selection in acquired SAA.

Methods: We conducted a multicenter study based on a registered database of 392 patients with SAA treated with allogeneic hematopoietic stem cell transplantation (allo-HSCT) between 2006 and 2018. In total, 223 patients received grafts from father donors, 47 from mother donors, 91 from siblings, 29 from children, and 2 from collateral donors.

Results: Of the 381 patients who survived more than 28 days, 379 (99.5\%) recipients were engrafted. The 2-year overall survival (OS) was $86.6 \pm 2.5 \%, 87.1 \pm 4.9 \%, 84.3 \pm 3.9 \%$, and $92.2 \pm 5.1 \%$ for recipients of father, mother, sibling, and child grafts, respectively, $(P=0.706)$. The 2 -year failure-free survival (FFS) was $82.8 \pm 2.7 \%, 86.7 \pm 5.1 \%, 80.8 \pm 4.2 \%$, and $92.5 \pm 5.1 \%$ for recipients of father, mother, sibling, and child grafts, respectively, $(P=0.508)$. There was no difference in the incidence of either acute or chronic graft-versus-host disease (GVHD) among the different donor sources in multivariate analyses. There were also no differences in the OS or FFS among the different donor sources in the Cox regression analysis. However, OS was significantly better in the patients with a shorter history of aplastic anemia ( $<12$ months), better performance status (ECOG scores $0-1)$, or moderate graft mononuclear cell (MNC) counts $\left(6-10 \times 10^{8} / \mathrm{kg}\right)$, and in female recipients with male donors. The FFS was also higher in patients with a shorter history of aplastic anemia ( $<12$ months) and better performance status (ECOG scores $0-1$ ).
\end{abstract}

Conclusions: Fathers, mothers, siblings, and children are all suitable haploidentical donors for patients with SAA.

Keywords: Haploidentical transplantation, Donor selection, Acquired severe aplastic anemia

\section{Background}

Severe aplastic anemia (SAA) is a life-threatening hematological disease characterized by an immune-mediated disorder of hematopoietic stem cells. Allogeneic hematological stem cell transplantation (HSCT) is recommended as the first-line treatment in young patients with an available matched sibling donor (MSD) and as

\footnotetext{
* Correspondence: xjhrm@medmail.com.cn

${ }^{\dagger}$ Lan-Ping Xu and Shun-Qing Wang contributed equally to this work.

${ }^{1}$ National Clinical Research Center for Hematologic Disease, Peking University

Institute of Hematology, Peking University People's Hospital, Beijing, China

${ }^{4}$ Beijing Key Laboratory of Hematopoietic Stem Cell Transplantation, Beijing, China

Full list of author information is available at the end of the article
}

the second-line treatment in older patients who failed immunosuppressive therapy (IST) $[1,2]$.

However, a significant number of patients requiring urgent HSCT lack an MSD. Moreover, the long-term effects of IST are far from satisfactory due to late sequelae, including relapse and the evolution to clonal diseases.

Under this condition, haploidentical donors (HIDs) have increasingly been proposed as an alternative in the absence of an MSD or a matched unrelated donor, and satisfactory outcomes after haploidentical HSCT have been recently reported [3-10]. The overall survival (OS) rate for HSCT with HIDs ranges from 67.1\% [5] to

(c) The Author(s). 2019 Open Access This article is distributed under the terms of the Creative Commons Attribution 4.0 International License (http://creativecommons.org/licenses/by/4.0/), which permits unrestricted use, distribution, and 
89.0\% [8-10], which is similar with that for MSD transplantation, indicating that they are equally effective [8].

Nearly all patients have at least one HLA-haploidentical related donor, and the selection algorithm of a haploidentical donor for hematological malignancies has been recommended [11-13]. Young, male, and noninherited maternal antigen (NIMA)-mismatched donors were associated with the best survival [11]. Optimal HID selection is essential in providing the recipients the best opportunity of a good outcome, but the best donor for SAA remains undefined. A few studies on HLA-identical HSCT for aplastic anemia have shown that male recipients of transplants from female grafts showed decreased survival compared with other donor-recipient sex matches $[3,14,15]$. In addition, for unrelated donors, older donor age ( $\geq 35$ years or $\geq 40$ years) is an adverse factor $[14,16]$. Thus, this study aimed to identify the best haploidentical donor for acquired severe aplastic anemia. Towards this goal, we compared the outcomes between different donor-recipient relationships.

\section{Methods}

\section{Patients and study design}

This multicenter study was conducted based on a registered database. We included patients with SAA who received a haploidentical transplant between 2006 and 2018 and who received standard busulfan (BU)/cyclophosphamide (CY) conditioning at Peking University Institute of Hematology $(n=274)$, Guangzhou First People's Hospital $(n=92)$, and the First Affiliated Hospital of Jilin University $(n=26)$. In total, 392 patients were enrolled in the study. The study protocol was approved by the institutional review board. All of the patients gave their written informed consent for the procedure.

\section{HLA typing}

Donor and recipient HLA-A, HLA-B, and HLA-DR1 were performed using high-resolution DNA techniques. All reagents (Special Monoclonal Tray-Asian HLA Class I and Micro SSP HLA Class I and II ABDR DNA Typing Tray; One Lambda, Canoga Park, CA) were approved by the FDA and commercially imported [17].

\section{Transplant protocols}

The transplantation procedure has been described in previous studies [8-10]. The uniform conditioning regimen consisted of busulfan (BU; $3.2 \mathrm{mg} / \mathrm{kg} / \mathrm{d}$, intravenous, days - 7 to - 6), cyclophosphamide (CY; $50 \mathrm{mg} / \mathrm{kg}$, days - 5 and - 2), and rabbit anti-thymocyte globulin (ATG; 2.5 $\mathrm{mg} / \mathrm{kg} / \mathrm{d}$, days -5 to -2 ). Bone marrow (BM) grafts were collected on day 1. Peripheral blood stem cells (PBSCs) were collected via apheresis using a COBE Blood Cell Separator (Gambro BCT, Lakewood, CO, USA) on day 2. All of the transplantation recipients received cyclosporine $\mathrm{A}$
(CsA), mycophenolate mofetil (MMF), and short-term methotrexate (MTX) as graft-versus-host disease (GVHD) prophylaxis. Intravenous CsA was administered starting at day -9 at a dose of $1.5 \mathrm{mg} / \mathrm{kg}$ q12h (trough level 200-250 $\mathrm{ng} / \mathrm{ml})$ in combination with of MTX $(15 \mathrm{mg} / \mathrm{m} 2$ day +1 , $10 \mathrm{mg} / \mathrm{m}^{2}$ on days $\left.+3,+6,+11\right)$. CsA was given orally once patients' bowel function returned to normal. The target concentration of CsA was required within a year posttransplant and was tapered and discontinued over the following 2-3 months. In addition, all patients began MMF orally (500 mg for adults and $250 \mathrm{mg}$ for children, q12h) on day -9 , tapered on day +30 , and discontinued on day +60 [9]. The recipients received $5 \mu \mathrm{g} / \mathrm{kg}$ subcutaneous G-CSF daily from day +6 until myeloid recovery. As previously described, all patients were hospitalized in a laminar airflow room and received prophylactic antibiotics during the neutropenic phase $[18,19]$.

\section{Definitions}

Neutrophil recovery was defined as the first of 3 consecutive days that an absolute neutrophil count $\geq 0.5 \times 10^{9} / \mathrm{L}$ was achieved, and platelet recovery was defined as the first of 7 consecutive days that a platelet count $\geq 20 \times 10^{9} / \mathrm{L}$ without transfusion was achieved. Donor recipient chimerism was confirmed by fluorescence in situ hybridization (FISH) for donor/recipient sex-mismatched pairs and by multiplex short tandem repeat (STR) polymerase chain reaction (PCR) for donor/recipient sex-matched pairs. Primary graft failure was defined when the neutrophil counts did not exceed $0.5 \times 10^{9} / \mathrm{L}$ for 3 consecutive days with low/absent donor chimerism at day 28 post-HSCT. Secondary graft failure or graft rejection was defined as neutropenia $\left(<0.5 \times 10^{9} / \mathrm{L}\right)$ with low/absent donor chimerism in patients with a prior history of engraftment. Patients with neutropenia $\left(<0.5 \times 10^{9} / \mathrm{L}\right)$ but complete donor chimerism were considered to have poor graft function (PGF) [20]. OS was calculated from the date of HSCT to death from any cause. Failure-free survival (FFS) was calculated from the date of HSCT to primary graft failure, secondary graft failure, PGF, second HSCT, or death [21, 22], with the patients alive at the last follow-up administratively censored. GVHD-free/relapse-free survival (GRFS) was calculated from the date of HSCT to the date of events that included grades III-IV acute GVHD, chronic GVHD requiring systemic therapy, relapse, or death [23]. The severity of acute GVHD and chronic GVHD was evaluated according to international criteria $[24,25]$.

\section{Statistical analysis}

The last follow-up date was February 1, 2019. The endpoint for the study was OS and FFS. The Kruskal-Wallis rank sum test was used for continuous variables, and the chi-square test or Fisher's exact test was used for 
categorical variables. All tests were two-sided. The Kaplan-Meier outcome curves for the OS, FFS, and GRFS were constructed for the 392 patients. The logrank test was used to identify prognostic factors, and a Cox proportional hazards regression model was used to assess the relative impact of previously defined risk factors in multivariate analysis. The cumulative incidences of graft failure and GVHD were calculated in a competing risk model, with death as the competing event. All factors with $P<0.10$ in univariate analysis along with the donor source were included in multivariate regression. A $P<0.05$ was considered significant. The data analyses were conducted primarily with SPSS software (SPSS, Chicago, IL, USA), and R software (version 2.6.1) (http://www.r-project.org).

\section{Results}

\section{Basic characteristics}

Table 1 shows the patient, disease, and transplant characteristics of the 392 patients in the study. Also shown in Table 1, the parental donors were older than the sibling donors (father vs. sibling, $P=0.000$; mother vs. sibling, $P=0.000$ ), and the sibling donors were older than the child donors $(P=0.007)$. There was a higher male/ female ratio of recipients in the sibling donor group, compared to the parental donor groups (father-child vs. sibling-sibling group, $P=0.010$; mother-child vs. siblingsibling group, $P=0.020$ ). The history of IST, the interval between diagnosis and transplant, and the infused cell number were similar among the different donor-recipient relationship groups. However, the median CD34+ cells were lower in the mother donor group than in the sibling donor group $(P=0.019)$ and the child donor group $(P=0.020)$.

\section{Engraftment}

Of the 381 patients who survived more than 28 days, 379 (99.5\%) achieved myeloid engraftment at a median time of 12 days (range, 9-31 days), and 365 patients $(95.8 \%)$ had platelet engraftment at a median time of 14 days (range, 5-180 days). One patient failed engraftment from father donor transplantation, and she had full chimerism after a second transplant from the mother donor. One patient who did not achieve engraftment after a sister donor graft remained in graft failure after a second transplantation from the same donor. This patient eventually underwent transplantation from a matched unrelated donor and achieved hematopoietic recovery. The cumulative incidence of neutrophil recovery at 28 days post-transplant was $96.4 \pm 0 \%$, and the cumulative incidence of platelet recovery at 100 days posttransplant was $91.3 \pm 0 \%$. Of the nine patients who experienced secondary graft failure (six from father grafts and three from brother grafts), two received a second transplant from the second haplo-donor, and one received an unrelated donor graft. All three patients achieved engraftment, but two of them died from an infection. Two patients who received second transplants from the same donor and another two patients who received donor lymphocyte infusion (DLI) did not achieve engraftment. The remaining two patients did not receive either second transplants or DLI.

Detection of donor-specific antibody (DSA) was performed in 196 of the 392 patients, and 14 patients (7.1\%) exhibited positive DSA. The proportions of positive DSA were $6.0 \%(n=8), 6.7 \%(n=1), 8.3 \%(n=3)$, and $20.0 \%$ $(n=2)$ in the father, mother, sibling, and child donor groups, respectively, $(P=0.417)$. Of the 11 patients with graft failure, DSA was measured in four patients, and one patient with primary graft failure had positive DSA.

\section{GVHD}

The cumulative incidence of grade II-IV aGVHD at 100 days was lower among the recipients of sibling grafts than that in parental transplants $(P=0.011)$. In the competing risk model, mother donor transplants had a higher rate of cGVHD (44.3 $\pm 0.6 \%$ vs. $27.1 \pm 0.1 \%, P=0.046)$ but not aGVHD (31.9 $\pm 0.5 \%$ vs. $39.9 \pm 0.1 \%, P=0.272)$ compared with father donor transplants (Table 2; Fig. 1). A higher degree of HLA mismatching was associated with a higher risk of grade II-IV aGVHD, but there were no significant differences in the risk of grade III-IV aGVHD and cGVHD. There were also no significant differences between NIMA and noninherited paternal antigen (NIPA) mismatched sibling donors in aGVHD and cGVHD.

In the multivariate analysis, patient age $<20$ years (vs. $\geq 20$ years, $\mathrm{HR}=1.863,95 \%$ CI $1.300-2.668, P=0.001)$ and a higher degree of HLA mismatches (3/6 vs. $5-6 / 6$, $\mathrm{HR}=4.702,95 \% \mathrm{CI} 1.161-19.037, P=0.030)$ were risk factors for grade II-IV aGVHD. Patient age $<20$ years (vs. $\geq 20$ years, $\mathrm{HR}=2.316,95 \%$ CI $1.081-4.962, P=0.031$ ) and $\mathrm{ABO}$ minor mismatch (vs. others, $\mathrm{HR}=2.817$, 95\% CI 1.438-5.519, $P=0.003$ ) remained significant prognostic factors for grade III-IV aGVHD in the multivariate model (Table 3).

Mother donor was the only risk factor for cGVHD in the Cox model (mother donor vs. father donor, $\mathrm{HR}=1.804$, 95\% CI 1.069-3.044, $P=0.027$ ) (Table 3). The Cox model did not reveal significant differences in CGVHD when the mother donors were compared to the sibling $(\mathrm{HR}=1.496$, 95\% CI $0.824-2.717, P=0.186$ ) or child donors $(\mathrm{HR}=1.158,95 \%$ CI $0.538-2.492, P=0.707)$. No significant factors in extensive cGVHD were identified in the multivariate analysis.

\section{Infection}

Of the 392 SAA patients, 298 (76.0\%) had virus infections, 85 (21.7\%) had bacterial infections, and $33(8.4 \%)$ 
Table 1 Patient, disease, and transplant characteristics

\begin{tabular}{|c|c|c|c|c|c|}
\hline \multirow[t]{2}{*}{ Characteristics } & \multicolumn{4}{|l|}{ Donor source } & \multirow[b]{2}{*}{ P } \\
\hline & $\begin{array}{l}\text { Father } \\
(N=223)\end{array}$ & $\begin{array}{l}\text { Mother } \\
(N=47)\end{array}$ & $\begin{array}{l}\text { Sibling } \\
(N=91)\end{array}$ & $\begin{array}{l}\text { Child } \\
(N=29)\end{array}$ & \\
\hline \multicolumn{6}{|l|}{ Patient age } \\
\hline Median (range), years & $12(1-36)$ & $11(4-30)$ & $27(4-55)$ & $43(29-54)$ & 0.000 \\
\hline$\geq 20$ years & $61(27.4 \%)$ & $14(29.8 \%)$ & $72(79.1 \%)$ & $29(100 \%)$ & 0.000 \\
\hline$<20$ years & $162(72.6 \%)$ & $33(70.2 \%)$ & 19 (20.9\%) & $0(0 \%)$ & \\
\hline Patient gender & & & & & 0.040 \\
\hline Male & 119 (53.4\%) & $23(48.9 \%)$ & $63(69.2 \%)$ & $18(62.1 \%)$ & \\
\hline Female & $104(46.6 \%)$ & $24(51.1 \%)$ & $28(30.8 \%)$ & $11(37.9 \%)$ & \\
\hline \multicolumn{6}{|l|}{ Donor age } \\
\hline Median (range), years & $41(24-63)$ & $37(20-54)$ & $28(7-53)$ & $16(10-28)$ & 0.000 \\
\hline$\geq 40$ years & 125 (56.1\%) & $19(40.4 \%)$ & $6(6.6 \%)$ & $0(0 \%)$ & 0.000 \\
\hline$<40$ years & $98(43.9 \%)$ & $28(59.6 \%)$ & $85(93.4 \%)$ & $29(100 \%)$ & \\
\hline Donor gender & & & & & 0.000 \\
\hline Male & $223(100 \%)$ & $0(0 \%)$ & $54(59.3 \%)$ & $19(65.5 \%)$ & \\
\hline Female & $0(0 \%)$ & $47(100 \%)$ & $37(40.7 \%)$ & $10(34.5 \%)$ & \\
\hline Donor-recipient gender & & & & & 0.000 \\
\hline Male to male & 119 (53.4\%) & $0(0 \%)$ & $40(44.0 \%)$ & $11(37.9 \%)$ & \\
\hline Female to male & $0(0 \%)$ & $23(48.9 \%)$ & $23(25.3 \%)$ & 7 (24.1\%) & \\
\hline Male to female & 104 (46.6\%) & $0(0 \%)$ & $14(15.4 \%)$ & $8(27.6 \%)$ & \\
\hline Female to female & $0(0 \%)$ & $24(51.1 \%)$ & $14(15.4 \%)$ & $3(10.3 \%)$ & \\
\hline \multicolumn{6}{|c|}{ Months from diagnosis to transplant } \\
\hline Median (range), months & $12(1-260)$ & $8(1-144)$ & $12(1-468)$ & $13(1-264)$ & 0.374 \\
\hline$<12$ months & $108(48.4 \%)$ & $28(59.6 \%)$ & $43(47.3 \%)$ & $11(37.9 \%)$ & 0.301 \\
\hline$\geq 12$ months & $115(51.6 \%)$ & $19(40.4 \%)$ & $48(52.7 \%)$ & $18(62.1 \%)$ & \\
\hline \multicolumn{6}{|l|}{ Transfusion before transplant } \\
\hline $\mathrm{RBC}$, median (range), $U$ & $20(1-600)$ & $17(0-180)$ & $20(2-300)$ & $16(2-160)$ & 0.724 \\
\hline PLT, median (range), $\mathrm{U}$ & $13.5(0-248)$ & $11.5(0-60)$ & $16(0-80)$ & $15(2-120)$ & 0.721 \\
\hline \multicolumn{6}{|l|}{ Ferritin } \\
\hline Median (range), ng/ml & $1701.5(9-20251)$ & $1801(189-7434)$ & $1978.5(23-10550)$ & $1904(197-8467)$ & 0.633 \\
\hline \multicolumn{2}{|c|}{ ECOG score pre-SCT, median (range) } & & & & 0.406 \\
\hline 0 & $55(24.7 \%)$ & 7 (14.9\%) & $17(18.7 \%)$ & $6(20.7 \%)$ & \\
\hline 1 & $121(54.3 \%)$ & $26(55.3 \%)$ & $57(62.6 \%)$ & $19(65.5 \%)$ & \\
\hline$\geq 2$ & $47(21.1 \%)$ & $14(29.8 \%)$ & $17(18.7 \%)$ & $4(13.8 \%)$ & \\
\hline \multicolumn{2}{|l|}{ Previous ATG treatment } & & & & 0.211 \\
\hline Yes & $42(18.8 \%)$ & $8(17.0 \%)$ & $14(15.6 \%)$ & $1(3.4 \%)$ & \\
\hline No & $181(81.2 \%)$ & $39(83.0 \%)$ & $77(84.6 \%)$ & $28(96.6 \%)$ & \\
\hline \multicolumn{2}{|l|}{ Matched HLA loci at A, B, DR } & & & & 0.032 \\
\hline $3 / 6$ & $188(84.3 \%)$ & $29(61.7 \%)$ & $68(74.7 \%)$ & $23(79.3 \%)$ & \\
\hline $4 / 6$ & $26(11.7 \%)$ & $13(27.7 \%)$ & $18(19.8 \%)$ & $5(17.2 \%)$ & \\
\hline $5-6 / 6$ & $9(4.0 \%)$ & $5(10.6 \%)$ & $5(5.5 \%)$ & $1(3.4 \%)$ & \\
\hline \multicolumn{2}{|c|}{ Donor-recipient $A B O$ match status } & & & & 0.326 \\
\hline Match & $124(55.6 \%)$ & $23(48.9 \%)$ & $46(50.5 \%)$ & $20(69.0 \%)$ & \\
\hline Minor mismatch & $47(21.1 \%)$ & $14(29.8 \%)$ & $15(16.5 \%)$ & $4(13.8 \%)$ & \\
\hline
\end{tabular}


Table 1 Patient, disease, and transplant characteristics (Continued)

\begin{tabular}{|c|c|c|c|c|c|}
\hline \multirow[t]{2}{*}{ Characteristics } & \multicolumn{4}{|l|}{ Donor source } & \multirow[b]{2}{*}{$P$} \\
\hline & $\begin{array}{l}\text { Father } \\
(N=223)\end{array}$ & $\begin{array}{l}\text { Mother } \\
(N=47)\end{array}$ & $\begin{array}{l}\text { Sibling } \\
(N=91)\end{array}$ & $\begin{array}{l}\text { Child } \\
(N=29)\end{array}$ & \\
\hline Major mismatch & $40(17.9 \%)$ & $8(17.0 \%)$ & $20(22.0 \%)$ & $3(10.3 \%)$ & \\
\hline Bidirectional mismatch & $12(5.4 \%)$ & $2(4.3 \%)$ & $10(11.0 \%)$ & $2(6.9 \%)$ & \\
\hline \multicolumn{6}{|l|}{ Number of nucleated cells } \\
\hline Median (range), $\times 10^{8} / \mathrm{kg}$ & $9.44(5.07-25.13)$ & $9.18(6.57-15.29)$ & $9.93(4.06-18.11)$ & $9.88(5.82-16.86)$ & 0.628 \\
\hline \multicolumn{6}{|l|}{ Number of CD34-positive cells } \\
\hline Median (range), $\times 10^{6} / \mathrm{kg}$ & $3.12(0.14-22.47)$ & $2.52(0.67-10.31)$ & $3.26(0.57-11.48)$ & $3.48(0.84-8.72)$ & 0.045 \\
\hline
\end{tabular}

had fungal infections. Cytomegalovirus (CMV) antigenemia occurred in 284 patients $(72.4 \%)$, and eight patients developed CMV diseases (four pneumonia, two enteritis, and two retinitis). Epstein-Barr virus (EBV) antigenemia occurred in 56 patients (14.3\%), and eight developed post-transplant lymphoproliferative disorders. No cases of adenovirus infection and toxoplasma were observed.

\section{Survival}

In total, $52(13.3 \%)$ patients died. The causes of death were GVHD in seven cases, infection in 20 cases, and other complications (in 25 cases). At a median follow-up of 743 days (range 125-4754 days), the OS, FFS, and GRFS were both similar among the recipients from different donor kinships. At last follow-up, 195 patients (87.4\%) in the father donor group, 40 (85.1\%) in the mother donor group, 77 (84.6\%) in the sibling donor group, 27 (93.1\%) in the child donor group, and one $(50 \%)$ in the collateral donor group were alive. The longterm outcomes of the patients are shown in Fig. 2.

In the Cox regression analysis, there were no differences in the OS and FFS according to the donor graft source, but both the OS and FFS were significantly better in the patients with a short history of aplastic anemia ( $\geq 12$ vs. $<12$ months, $\mathrm{HR}=1.876,95 \%$ CI $1.057-3.328$, $P=0.032$ ), and better performance status (ECOG scores $2-3$ vs. $0-1, \mathrm{HR}=3.605,95 \%$ CI $2.028-6.409, P=0.000)$. The 2-year OS rate of the male-to-female transplants was higher than that of other sex-matched groups $(92.1 \pm 2.5 \%$ vs. $83.5 \pm 2.4 \%)$ in the Kaplan-Meier survival curve, and male-to-female donations remained a significantly beneficial prognostic factor for the OS in the multivariate analysis $(\mathrm{HR}=0.433,95 \% \mathrm{CI} 0.210-0.889, P=0.023)$. Moderate MNC counts of $6-10 \times 10^{8} / \mathrm{kg}$ were also a protective factor against death (for OS, $\mathrm{HR}=0.440,95 \% \mathrm{CI}$ $0.249-0.778, P=0.005)$. The covariates that were significant for GRFS included ABO minor mismatch, MNC counts, and ECOG score (Table 3).

There were no statistically significant differences in OS or FFS between NIMA- and NIPA-mismatched sibling donor transplants (OS $80.6 \pm 7.1 \%$ vs. $83.5 \pm 6.2 \%, P=0.066$; FFS $80.6 \pm 7.1 \%$ vs. $83.4 \pm 6.2 \%, P=0.708)$.

\section{Subgroup analysis}

In the subgroup analysis, for the female recipients, female donors were associated with worse OS than male donors in the multivariate analysis $(\mathrm{HR}=2.581,95 \% \mathrm{CI}$ 0.990-6.728, $P=0.052$ ). In contrast, female donors were not associated with worse survival when the recipient was male (male donors vs. female donors: 2-year OS, $81.4 \pm 3.2 \%$ vs. $92.3 \pm 3.7 \%, P=0.150$; 2 -year FFS, 79.0 $\pm 3.3 \%$ vs. $87.4 \pm 4.9 \%, P=0.387$, respectively).

In total, 29 patients received child grafts (19 from sons and 10 from daughters). There were no differences in OS, FFS, and GVHD between son donor and daughter donors (2-year OS: $88.4 \pm 7.8 \%$ vs. $100 \%, P=0.289$; 2 -year FFS: $88.4 \pm 7.8 \%$ vs. $100 \%, P=0.289$; grade II-IV aGVHD: $26.3 \%$ vs. $10.0 \%, P=0.301$; grade III-IV aGVHD: $5.3 \%$ vs. $0 \%, P=0.468$; cGVHD: $48.1 \%$ vs. $32.5 \%, P=0.503$; extensive cGVHD: $5.6 \%$ vs. $10.0 \%, P=0.723$ ).

There were 91 patients who received sibling donor grafts. Regarding male donor to male patient (M-M), female donor to male patient (F-M), male donor to female patient (M-F), and female donor to female patient (F-F), the 2 -year OS was $82.1 \pm 6.2 \%, 90.9 \pm 6.2 \%, 92.9 \pm 6.9 \%$, and $71.4 \pm 12.1 \%(P=0.308)$, respectively. The 2-year FFS for M-M, F-M, M-F, and F-F was $82.5 \pm 6.0 \%$, $80.2 \pm 9.0 \%, 84.6 \pm 10.0 \%$, and $71.4 \pm 12.1 \%(P=0.773)$, respectively. There were no differences in either aGVHD or cGVHD between different donor-recipient sex matches.

For pediatric patients, the Cox models for OS and FFS revealed a significant influence of better performance status (ECOG scores $2-3$ vs. $0-1$; OS: HR $=5.312$, 95\% CI 2.092-13.487, $P=0.000$; FFS: HR $=3.547,95 \% \mathrm{CI}$ 1.585-7.937, $P=0.002)$. Donor-to-recipient sex match, the duration from diagnosis to transplant, and $\mathrm{MNC}$ counts did not affect OS and FFS for pediatrics. ABO minor mismatch remained a significant risk factor for grade III-IV aGVHD (ABO minor mismatch vs. others, $\mathrm{HR}=3.467,95 \% \mathrm{CI} 1.520-7.909, P=0.003)$. No 
Table 2 Univariate analysis of donor-related characteristics on transplant outcomes

\begin{tabular}{|c|c|c|c|c|c|c|}
\hline Risk factors & II-IV aGVHD & III-IV aGVHD & Chronic GVHD & Extensive cGVHD & FFS & OS \\
\hline Relationship & \multicolumn{2}{|c|}{ 100d estimated cumulative incidence } & \multicolumn{4}{|c|}{ 2-year estimated cumulative incidence or probability } \\
\hline Paternal donor & $39.9 \% \pm 0.1 \%$ & $9.4 \% \pm 0.0 \%$ & $27.1 \% \pm 0.1 \%$ & $10.3 \% \pm 0.1 \%$ & $82.8 \% \pm 2.7 \%$ & $86.5 \% \pm 2.5 \%$ \\
\hline Maternal donor & $31.9 \% \pm 0.5 \%$ & $14.9 \% \pm 0.3 \%$ & $44.3 \% \pm 0.6 \%$ & $11.9 \% \pm 0.3 \%$ & $86.7 \% \pm 5.1 \%$ & $87.1 \% \pm 4.9 \%$ \\
\hline Sibling donor & $25.3 \% \pm 0.2 \%$ & $5.5 \% \pm 0.1 \%$ & $29.5 \% \pm 0.3 \%$ & $7.5 \% \pm 0.1 \%$ & $80.8 \% \pm 4.2 \%$ & $84.3 \% \pm 3.9 \%$ \\
\hline Offspring donor & $20.7 \% \pm 0.6 \%$ & $3.4 \% \pm 0.1 \%$ & $40.6 \% \pm 1.2 \%$ & $7.2 \% \pm 0.2 \%$ & $92.5 \% \pm 5.1 \%$ & $92.5 \% \pm 5.1 \%$ \\
\hline$P$ & 0.026 & 0.202 & 0.175 & 0.843 & 0.508 & 0.706 \\
\hline Paternal donor & $39.9 \% \pm 0.1 \%$ & $9.4 \% \pm 0.0 \%$ & $27.1 \% \pm 0.1 \%$ & $10.3 \% \pm 0.1 \%$ & $82.8 \% \pm 2.7 \%$ & $86.5 \% \pm 2.5 \%$ \\
\hline Maternal donor & $31.9 \% \pm 0.5 \%$ & $14.9 \% \pm 0.3 \%$ & $44.3 \% \pm 0.6 \%$ & $11.9 \% \pm 0.3 \%$ & $86.7 \% \pm 5.1 \%$ & $87.1 \% \pm 4.9 \%$ \\
\hline P & 0.272 & 0.282 & 0.046 & 0.780 & 0.937 & 0.755 \\
\hline Sibling donor & $25.3 \% \pm 0.2 \%$ & $5.5 \% \pm 0.1 \%$ & $29.5 \% \pm 0.3 \%$ & $7.5 \% \pm 0.1 \%$ & $80.8 \% \pm 4.2 \%$ & $84.3 \% \pm 3.9 \%$ \\
\hline Offspring donor & $20.7 \% \pm 0.6 \%$ & $3.4 \% \pm 0.1 \%$ & $40.6 \% \pm 1.2 \%$ & $7.2 \% \pm 0.2 \%$ & $92.5 \% \pm 5.1 \%$ & $92.5 \% \pm 5.1 \%$ \\
\hline$P$ & 0.697 & 0.670 & 0.333 & 0.858 & 0.130 & 0.252 \\
\hline Paternal donor & $39.9 \% \pm 0.1 \%$ & $9.4 \% \pm 0.0 \%$ & $27.1 \% \pm 0.1 \%$ & $10.3 \% \pm 0.1 \%$ & $82.8 \% \pm 2.7 \%$ & $86.5 \% \pm 2.5 \%$ \\
\hline Sibling donor & $25.3 \% \pm 0.2 \%$ & $5.5 \% \pm 0.1 \%$ & $29.5 \% \pm 0.3 \%$ & $7.5 \% \pm 0.1 \%$ & $80.8 \% \pm 4.2 \%$ & $84.3 \% \pm 3.9 \%$ \\
\hline$P$ & 0.011 & 0.238 & 0.699 & 0.445 & 0.478 & 0.475 \\
\hline \multicolumn{7}{|l|}{ Donor age } \\
\hline$<30$ & $27.2 \% \pm 0.2 \%$ & $4.9 \% \pm 0.0 \%$ & $35.0 \% \pm 0.3 \%$ & $9.2 \% \pm 0.1 \%$ & $85.8 \% \pm 3.5 \%$ & $88.2 \% \pm 3.2 \%$ \\
\hline$\geq 30$ & $36.3 \% \pm 0.1 \%$ & $10.0 \% \pm 0.0 \%$ & $29.1 \% \pm 0.1 \%$ & $9.7 \% \pm 0.0 \%$ & $82.3 \% \pm 2.4 \%$ & $85.6 \% \pm 2.2 \%$ \\
\hline$P$ & 0.104 & 0.106 & 0.194 & 0.815 & 0.538 & 0.659 \\
\hline$<40$ & $32.0 \% \pm 0.1 \%$ & $7.5 \% \pm 0.0 \%$ & $28.9 \% \pm 0.1 \%$ & $7.5 \% \pm 0.0 \%$ & $86.1 \% \pm 2.3 \%$ & $88.4 \% \pm 2.1 \%$ \\
\hline$\geq 40$ & $37.1 \% \pm 0.2 \%$ & $10.6 \% \pm 0.1 \%$ & $32.9 \% \pm 0.2 \%$ & $12.5 \% \pm 0.1 \%$ & $79.0 \% \pm 3.5 \%$ & $83.4 \% \pm 3.2 \%$ \\
\hline$P$ & 0.383 & 0.303 & 0.463 & 0.162 & 0.104 & 0.187 \\
\hline \multicolumn{7}{|l|}{ Donor sex } \\
\hline Male & $35.9 \% \pm 0.1 \%$ & $8.1 \% \pm 0.0 \%$ & $28.3 \% \pm 0.1 \%$ & $9.1 \% \pm 0.0 \%$ & $82.9 \% \pm 2.3 \%$ & $86.0 \% \pm 2.2 \%$ \\
\hline Female & $27.7 \% \pm 0.2 \%$ & $10.6 \% \pm 0.1 \%$ & $37.8 \% \pm 0.3 \%$ & $10.8 \% \pm 0.1 \%$ & $84.3 \% \pm 3.9 \%$ & $87.1 \% \pm 3.5 \%$ \\
\hline$P$ & 0.137 & 0.459 & 0.144 & 0.666 & 0.901 & 0.871 \\
\hline \multicolumn{7}{|l|}{ Donor-recipient sex } \\
\hline Male-male & $36.0 \% \pm 0.1 \%$ & $7.0 \% \pm 0.0 \%$ & $27.2 \% \pm 0.1 \%$ & $9.7 \% \pm 0.1 \%$ & $79.0 \% \pm 3.3 \%$ & $81.4 \% \pm 3.2 \%$ \\
\hline Female-male & $22.6 \% \pm 0.3 \%$ & $9.4 \% \pm 0.2 \%$ & $40.3 \% \pm 0.6 \%$ & $17.2 \% \pm 0.3 \%$ & $87.4 \% \pm 4.9 \%$ & $92.3 \% \pm 3.7 \%$ \\
\hline Male-female & $35.7 \% \pm 0.2 \%$ & $9.5 \% \pm 0.1 \%$ & $30.0 \% \pm 0.2 \%$ & $8.6 \% \pm 0.1 \%$ & $88.2 \% \pm 3.0 \%$ & $92.1 \% \pm 2.5 \%$ \\
\hline Female-female & $34.1 \% \pm 0.6 \%$ & $12.2 \% \pm 0.3 \%$ & $34.7 \% \pm 0.7 \%$ & $2.6 \% \pm 0.1 \%$ & $80.5 \pm 6.2 \%$ & $80.3 \% \pm 6.2 \%$ \\
\hline$P$ & 0.324 & 0.711 & 0.459 & 0.175 & 0.251 & 0.030 \\
\hline \multicolumn{7}{|l|}{ HLA match } \\
\hline $3 / 6$ & $36.8 \% \pm 0.1 \%$ & $5.0 \% \pm 0.3 \%$ & $28.9 \% \pm 0.1 \%$ & $7.6 \% \pm 0.0 \%$ & $83.7 \% \pm 2.2 \%$ & $86.8 \% \pm 2.0 \%$ \\
\hline $4 / 6$ & $27.4 \% \pm 0.3 \%$ & $6.5 \% \pm 0.1 \%$ & $31.7 \% \pm 0.4 \%$ & $16.4 \% \pm 0.3 \%$ & $79.3 \% \pm 5.8 \%$ & $82.6 \% \pm 5.1 \%$ \\
\hline $5-6 / 6$ & $10.0 \% \pm 0.5 \%$ & $9.4 \% \pm 0.0 \%$ & $54.5 \% \pm 1.7 \%$ & $17.5 \% \pm 0.9 \%$ & $88.2 \% \pm 8.0 \%$ & $89.1 \% \pm 7.3 \%$ \\
\hline$P$ & 0.019 & 0.616 & 0.307 & 0.096 & 0.578 & 0.551 \\
\hline \multicolumn{7}{|l|}{ ABO blood type } \\
\hline Match & $30.8 \% \pm 0.1 \%$ & $4.7 \% \pm 0.0 \%$ & $31.4 \% \pm 0.1 \%$ & $8.5 \% \pm 0.0 \%$ & $82.1 \% \pm 2.8 \%$ & $86.5 \% \pm 2.5 \%$ \\
\hline Minor mismatch & $42.0 \% \pm 0.3 \%$ & $17.3 \% \pm 0.2 \%$ & $32.7 \% \pm 0.3 \%$ & $9.9 \% \pm 0.1 \%$ & $84.7 \% \pm 4.1 \%$ & $87.4 \% \pm 3.7 \%$ \\
\hline Major mismatch & $32.3 \% \pm 0.3 \%$ & $9.9 \% \pm 0.1 \%$ & $20.7 \% \pm 0.3 \%$ & $10.0 \% \pm 0.2 \%$ & $87.8 \% \pm 4.1 \%$ & $87.8 \% \pm 4.1 \%$ \\
\hline Bidirectional mismatch & $38.5 \% \pm 1.0 \%$ & $11.5 \% \pm 0.4 \%$ & $43.5 \% \pm 1.1 \%$ & $15.6 \% \pm 0.5 \%$ & $75.7 \% \pm 8.8 \%$ & $77.0 \% \pm 8.3 \%$ \\
\hline$P$ & 0.415 & 0.007 & 0.162 & 0.668 & 0.490 & 0.517 \\
\hline
\end{tabular}



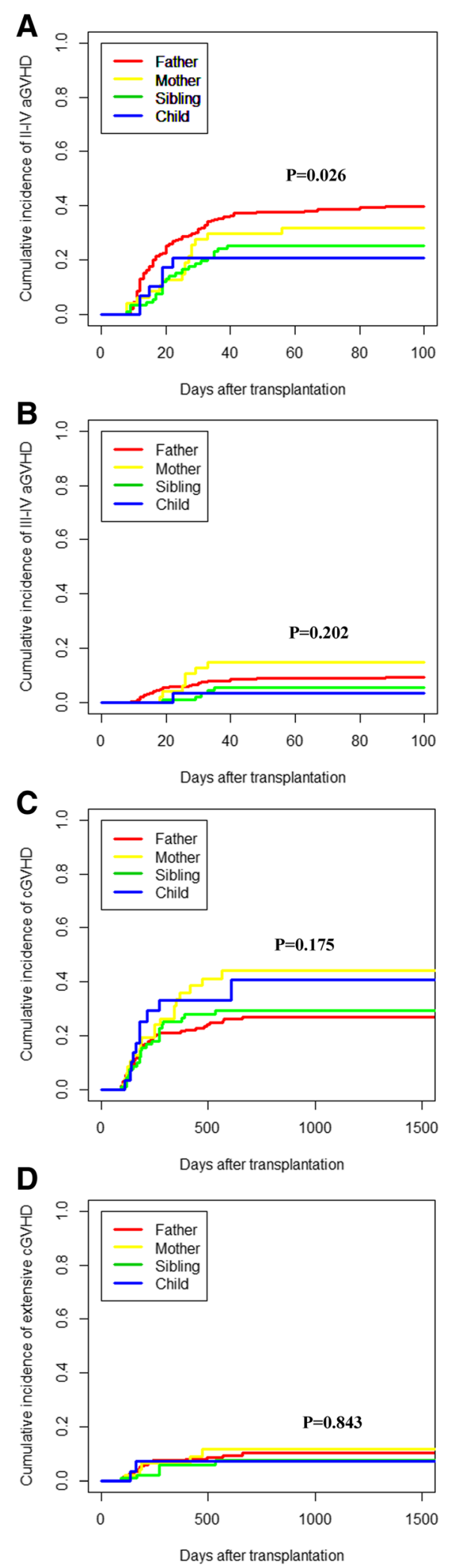

Fig. 1 a Grade II-IV aGVHD in different donor kinships. b Grade III-IV aGVHD in different donor kinships. c cGVHD in different donor kinships. d Extensive cGVHD in different donor kinships

significant clinical factors were found to be associated with grade II-IV aGVHD, cGVHD, and extensive cGVHD.

For adult patients, the significant covariates for OS were better performance status (ECOG scores $2-3$ vs. $0-1$, HR $=3.473,95 \%$ CI $1.610-7.489, P=0.001)$, and moderate MNC counts of $6-10 \times 10^{8} / \mathrm{kg}(\mathrm{HR}=0.282,95 \% \mathrm{CI}$ $0.131-0.608, P=0.001$ ). These two factors were also significant in the Cox model for FFS (ECOG scores $2-3$ vs. $0-1, \mathrm{HR}=2.627,95 \% \mathrm{CI} 1.247-5.534, P=0.011$; moderate $\mathrm{MNC}$ counts of $6-10 \times 10^{8} / \mathrm{kg}$ vs. others, $\mathrm{HR}=0.345$, 95\% CI 0.169-0.704, $P=0.003$ ). Meanwhile, we did not find any statistically significant factors for GVHD.

\section{Discussion}

In this study, we compared the outcomes between different donor-recipient relationships to help prioritize haploidentical donors for SAA to improve survival after haploidentical transplantation.

We found that maternal grafts were not associated with poorer survival outcomes. Our previous results on leukemia suggested that the survival of transplantation from mother to child was inferior to that from other family relationships in haploidentical HSCT, probably due to the higher probability of GVHD and nonrelapse mortality (NRM) [11]. Wang et al. compared the outcomes of mother donor transplants and contemporaneous transplants using allografts from father donors, and the rate of grade II-IV aGVHD, rate of cGVHD rate, NRM, and survival in the mother donor cohort versus father donor cohort were $52 \%$ vs. $40 \%, 57 \%$ vs. $48 \%, 21 \%$ vs. $13 \%$, and $64 \%$ vs. $74 \%$, respectively [11]. There are several possible reasons for the inconsistent outcomes between the current and previous studies. First might be the different conditioning regimens between hematological malignancies and aplastic anemia. Cyclophosphamide was a regular approach for immunological tolerance induction in haploidentical HSCT and was given to the SAA patients in this study at a total dose of $200 \mathrm{mg} / \mathrm{kg}$ on days -5 to $-2[26,27]$. Thus, at a higher drug dose, it seemed plausible that enhanced in vivo graft-host tolerance was induced. Secondly, in recent years, progress in the understanding, prophylaxis, and therapeutic intervention for GVHD has reduced the probability and severity of GVHD [28, 29], and the discovery of predictive and prognostic biomarkers might be helpful for individualized GVHD prophylaxis [30]. Further, the mother donor group had a higher frequency of $\mathrm{ABO}$ minor mismatch. Because ABO minor mismatch was related to grade III-IV aGVHD, we also analyzed the underlying factor of blood type that might intensify the association between mother donor and cGVHD. However, no influence of $\mathrm{ABO}$ blood type on cGVHD was detected in either univariate or multivariate models. 
Table 3 Risk factors for survival and GVHD: Cox regression analysis

\begin{tabular}{|c|c|c|c|}
\hline Risk factor & Relative risk & $95 \% \mathrm{Cl}$ & $P$ value \\
\hline \multicolumn{4}{|l|}{ II-IV aGVHD } \\
\hline Patient age $<20$ years vs. $\geq 20$ years & 1.863 & $1.300-2.668$ & 0.001 \\
\hline HLA $3 / 6$ vs. $5-6 / 6$ & 4.702 & $1.161-19.037$ & 0.030 \\
\hline HLA $3 / 6$ vs. $4 / 6$ & 1.509 & $0.906-2.512$ & 0.114 \\
\hline \multicolumn{4}{|l|}{ III-IV aGVHD } \\
\hline Patient age $<20$ years vs. $\geq 20$ years & 2.316 & $1.081-4.962$ & 0.031 \\
\hline$A B O$ minor mismatch vs. others & 2.817 & $1.438-5.519$ & 0.003 \\
\hline \multicolumn{4}{|l|}{ cGVHD } \\
\hline Mother donor vs. father donor & 1.804 & $1.069-3.044$ & 0.027 \\
\hline \multicolumn{4}{|l|}{ Overall survival } \\
\hline Male to female vs. others & 0.433 & $0.210-0.889$ & 0.023 \\
\hline Months from diagnosis to transplant $\geq 12$ vs. $<12$ & 1.876 & $1.057-3.328$ & 0.032 \\
\hline ECOG 2-3 vs. 0-1 & 3.605 & $2.028-6.409$ & 0.000 \\
\hline MNC $6-10 \times 10^{8} / \mathrm{kg}$ vs. Others & 0.440 & $0.249-0.778$ & 0.005 \\
\hline \multicolumn{4}{|l|}{ Failure-free survival } \\
\hline Months from diagnosis to transplant $\geq 12$ vs. $<12$ & 1.907 & $1.124-3.235$ & 0.017 \\
\hline ECOG 2-3 vs. 0-1 & 2.388 & $1.414-4.032$ & 0.001 \\
\hline \multicolumn{4}{|l|}{ GVHD-free/relapse-free survival } \\
\hline$A B O$ minor mismatch vs. others & 1.856 & $1.245-2.765$ & 0.002 \\
\hline ECOG 2-3 vs. 0-1 & 1.589 & $1.016-2.486$ & 0.043 \\
\hline MNC $6-10 \times 10^{8} / \mathrm{kg}$ vs. Others & 0.642 & $0.433-0.953$ & 0.028 \\
\hline
\end{tabular}

aGVHD acute graft-versus-host disease, $c G V H D$ chronic graft-versus-host disease, ECOG Eastern Cooperative Oncology Group, MNC mononuclear cell

In our cohort, although the mother donor group had a higher incidence of cGVHD than the father donor group, the mother donor group did not demonstrate more frequent cGVHD compared to the sibling or child donor groups, and the rates of aGVHD and extensive cGVHD were similar between the mother donor group and other donor groups.

In haploidentical transplants for hematological malignancies, the number of HLA locus disparities was not significantly correlated with transplant outcomes [11]. However, in this population of haploidentical transplants for SAA, we found transplants with HLA mismatches of 0 or 1 locus had a lower rate of grade II-IV aGVHD than those with three loci HLA mismatches. As mentioned above, the inconsistent outcomes between hematological malignancies and SAA might be due to the different physiology between the two diseases and the different conditioning regimens used.

Our findings are in line with a study showing a higher rate of III-IV aGVHD in the minor ABO-mismatched group in 154 unrelated donor transplants [31]. In 154 cases, Ludajic et al. reported that the cumulative incidence of III-IV aGVHD was $37 \%$ in the minor $\mathrm{ABO}$-mismatched group compared to $18 \%$ in the $\mathrm{ABO}$-matched group, $10 \%$ in the major $\mathrm{ABO}$-mismatched group, and $14 \%$ in the bidirectional $\mathrm{ABO}-$ mismatched group. Compared to the $\mathrm{ABO}$-matched group, the risk of III-IV aGVHD was approximately 4-fold high in the minor ABO-mismatched group [31]. Ozkurt et al. reported more frequent severe aGVHD among minor ABO-mismatched patients [32], but Kimura et al. found a high incidence of severe aGVHD in both major and minor $\mathrm{ABO}$ mismatches [33]. There were also conflicting results that failed to find a difference in rates of aGVHD between minor $\mathrm{ABO}$ incompatibility and others [34-36]. No evidence of an association between the $\mathrm{ABO}$ mismatch and cGVHD or survival was observed in this study. As the recipient A or B antigens are also expressed on their endothelial and epithelial cells, the mechanism of more severe aGVHD in minor ABO mismatches is likely to be the immunization of donor B lymphocytes against recipient antigens inducing GVHD. Most studies investigating the effect of $A B O$ mismatches on GVHD were based on hematological malignancies and mostly unrelated donor transplants. For SAA patients, we found that minor ABO mismatch was a detrimental factor for severe aGVHD in haploidentical transplantation. 


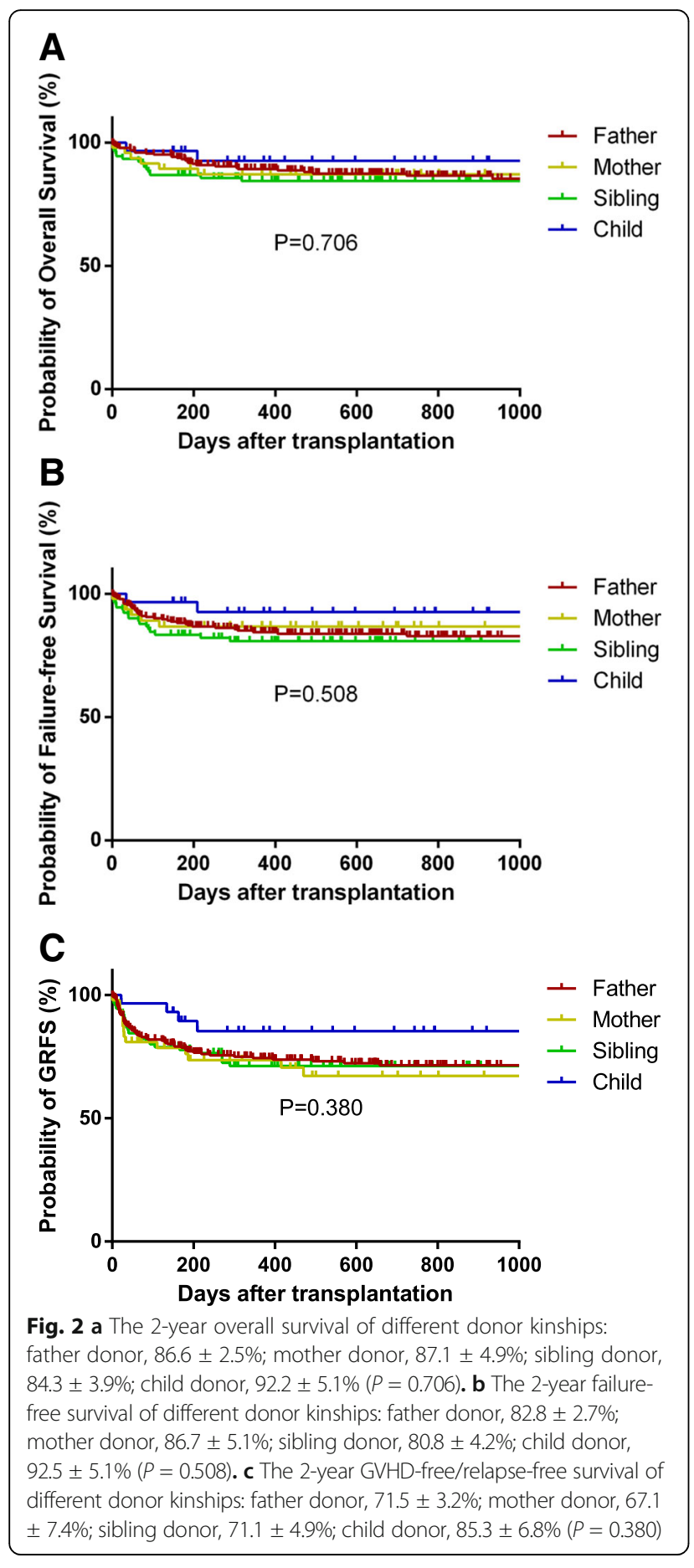

In this SAA population, the OS and FFS were better in patients receiving moderate $\mathrm{MNC}$ counts. The target count of MNC was $6-8 \times 10^{8} / \mathrm{kg}$ in haploidentical allogeneic transplantation for SAA, while in our clinical practice, the MNC count infused ranged from 6 to $10 \times$ $10^{8} / \mathrm{kg}$ [9]. In this population, preliminary analysis showed that MNC counts of $6-10 \times 10^{8} / \mathrm{kg}$ were better than $<6$ and $>10 \times 10^{8} / \mathrm{kg}$ for survival. Thus, we recommended $6-10 \times 10^{8} / \mathrm{kg}$ as a moderate range of MNC counts. The lower CD34+ cell harvest from mother donors is an interesting phenomenon. Previous studies showed that age, sex, and body mass index (BMI) might be associated with CD34+ cell count yield, but this association is still controversial [37-39]. Our previous study on the impact of donor characteristics on the immune cell composition showed that donor sex was not correlated with the yield of CD34+ stem cells [38]. However, in this study, female donors had lower CD34+ cell counts than men (median, $2.63 \times 10^{6} / \mathrm{kg}$ vs. $\left.3.33 \times 10^{6} / \mathrm{kg}, P=0.020\right)$. In another study, the researchers observed a lower post-G-CSF CD34+ cell count in female donors than in men, and they speculated that this difference might be because female donors weighed less than male donors and received lower total amounts of G-CSF [39]. Chen et al. also reported that female donors were less excellent responders in terms of CD34+ cell count [40]. However, there are currently no data on the relationship between mother donors and CD34+ cell collection and the results need further validation.

Female donation to a male recipient was regarded as an adverse prognostic factor in transplantation for hematological malignancies $[41,42]$ and in HLAmatched HSCT for SAA $[14,15]$. In a multicenter study of aplastic anemia, Stern et al. reported decreased survival and increased risk of rejection in female patients with male donors compared to recipients of sex-matched grafts [15]. By contrast, we observed that female recipients with male donors had better survival than recipients of sex-matched grafts. However, the reason for this finding remains unknown. The importance of donor sex and age for SAA in allogeneic HSCT has been widely studied $[14,15]$. Grafts from younger donors have been reported to be a favorable factor for survival after haploidentical transplantation for SAA [14, 16]. However, older donors were not associated with more GVHD or worse survival than younger donors in our study.

A potential limitation of this retrospective study is that based on the current decision-making for donor selection in hematologic malignancies, mother donors are rarely selected. Therefore, improvement in the SAA survival of maternal graft transplantation might be partially underestimated. Even so, the mother donor group still demonstrated comparable outcomes with other donor groups, thus showing that maternal grafts were not inferior to grafts from other donors. Although our data showed that male donors for female recipients might be superior to female donors, this finding was drawn from limited data and is not supported by previous reports. 
Therefore, the results may not be generalizable to other transplant patterns, and prospective studies are warranted.

\section{Conclusion}

In conclusion, fathers, mothers, siblings, and children are all suitable HIDs for patients with SAA. Despite the higher incidence of cGVHD in mother donors, survival outcomes were comparable for father, mother, sibling, and child donor transplantation. To reduce the risk of severe aGVHD, avoiding donor-recipient $\mathrm{ABO}$ blood minor mismatch should be considered. These findings provide a basis for the selection of optimal HIDs for SAA.

\begin{abstract}
Abbreviations
aGVHD: Acute graft-versus-host disease; allo-HSCT: Allogeneic hematopoietic stem cell transplantation; ATG: Anti-thymocyte globulin; BM: Bone marrow; BU: Busulfan; CGVHD: Chronic graft-versus-host disease; CsA: Cyclosporin A; CY: Cyclophosphamide; ECOG: Eastern Cooperative Oncology Group; FFS: Failure-free survival; FISH: Fluorescence in situ hybridization; GRFS: GVHDfree/relapse-free survival; HID: Haploidentical donor; HSCT: Hematopoietic stem cell transplantation; IST: Immunosuppressive therapy; MMF: Mycophenolate mofetil; MNC: Mononuclear cell; MSD: Matched sibling donor; MTX: Methotrexate; NIMA: Noninherited maternal antigen; NIPA: Noninherited paternal antigen; NRM: Nonrelapse mortality; OS: Overall survival; PBSCs: Peripheral blood stem cells; PCR: Polymerase chain reaction; PGF: Poor graft function; PTLD: Post-transplant lymphoproliferative disorders; SAA: Severe aplastic anemia; STR: Short tandem repeat
\end{abstract}

\section{Acknowledgements}

We thank all of our colleagues for participating in this research.

\section{Authors' contributions}

$\mathrm{X}-\mathrm{JH}$ designed the study, L-PX and S-QW analyzed the data and wrote the manuscript, and all coauthors contributed the patients' data and approved the final manuscript.

\section{Funding}

This work was partially supported by grants from the Innovative Research Groups of the National Natural Science Foundation of China (grant numbers 81670167, 81621001, and 81530046) and the National Key Research and Development Program of China (grant number 2017YFA0104500).

\section{Availability of data and materials}

The datasets used and/or analyzed during the current study are available from the corresponding author on reasonable request.

\section{Ethics approval and consent to participate}

The study was approved by each institutional review board at the three participating institutions, and written informed consent was obtained from all subjects in accordance with the Declaration of Helsinki.

\section{Consent for publication}

Not applicable.

\section{Competing interests}

The authors declare that they have no competing interests.

\section{Author details}

${ }^{1}$ National Clinical Research Center for Hematologic Disease, Peking University Institute of Hematology, Peking University People's Hospital, Beijing, China. ${ }^{2}$ Department of Hematology, Guangzhou First People's Hospital, School of Medicine, South China University of Technology, Guangzhou, China. ${ }^{3}$ The First Hospital of Jilin University, Changchun, China. ${ }^{4}$ Beijing Key Laboratory of Hematopoietic Stem Cell Transplantation, Beijing, China. ${ }^{5}$ Peking-Tsinghua Center for Life Sciences, Beijing, China.
Received: 6 June 2019 Accepted: 16 August 2019

Published online: 02 September 2019

\section{References}

1. Bacigalupo A. How I treat acquired aplastic anemia. Blood. 2017;129:1428-36.

2. Killick SB, Bown N, Cavenagh J, Dokal I, Foukaneli T, Hill A, et al. Guidelines for the diagnosis and management of adult aplastic anaemia. $\mathrm{Br} J$ Haematol. 2016;172:187-207.

3. Clay J, Kulasekararaj AG, Potter V, Grimaldi F, McLornan D, Raj K, et al. Nonmyeloablative peripheral blood haploidentical stem cell transplantation for refractory severe aplastic anemia. Biol Blood Marrow Transpl. 2014;20: 1711-6.

4. Dezern AE, Luznik L, Fuchs EJ, Jones RJ, Brodsky RA. Post-transplantation cyclophosphamide for GVHD prophylaxis in severe aplastic anemia. Bone Marrow Transpl. 2011;46:1012-3.

5. Esteves I, Bonfim C, Pasquini R, Funke V, Pereira NF, Rocha V, et al. Haploidentical BMT and post-transplant Cy for severe aplastic anemia: a multicenter retrospective study. Bone Marrow Transpl. 2015;50:685-9.

6. Gao L, Li Y, Zhang Y, Chen X, Gao L, Zhang C, et al. Long-term outcome of HLA-haploidentical hematopoietic SCT without in vitro Tcell depletion for adult severe aplastic anemia after modified conditioning and supportive therapy. Bone Marrow Transpl. 2014;49: 519-24.

7. Passweg JR, Perez WS, Eapen M, Camitta BM, Gluckman E, Hinterberger $W$, et al. Bone marrow transplants from mismatched related and unrelated donors for severe aplastic anemia. Bone Marrow Transpl. 2006;37:641-9.

8. Xu LP, Jin S, Wang SQ, Xia LH, Bai H, Gao SJ, et al. Upfront haploidentical transplant for acquired severe aplastic anemia: registrybased comparison with matched related transplant. J Hematol Oncol. 2017;10:25.

9. Xu LP, Wang SQ, Wu DP, Wang JM, Gao SJ, Jiang M, et al. Haploidentical transplantation for acquired severe aplastic anaemia in a multicentre prospective study. Br J Haematol. 2016;175:265-74.

10. Xu LP, Xu ZL, Wang FR, Mo XD, Han T, Han W, et al. Unmanipulated haploidentical transplantation conditioning with busulfan, cyclophosphamide and anti-thymoglobulin for adult severe aplastic anaemia. Bone Marrow Transpl. 2018;53:188-92.

11. Wang Y, Chang YJ, Xu LP, Liu KY, Liu DH, Zhang XH, et al. Who is the best donor for a related HLA haplotype-mismatched transplant? Blood. 2014;124:843-50.

12. Ciurea SO, Champlin RE. Donor selection in T cell-replete haploidentical hematopoietic stem cell transplantation: knowns, unknowns, and controversies. Biol Blood Marrow Transpl. 2013;19:180-4.

13. Kasamon YL, Luznik L, Leffell MS, Kowalski J, Tsai HL, Bolanos-Meade $J$, et al. Nonmyeloablative HLA-haploidentical bone marrow transplantation with high-dose posttransplantation cyclophosphamide: effect of HLA disparity on outcome. Biol Blood Marrow Transpl. 2010; 16:482-9.

14. Kojima S, Matsuyama T, Kato S, Kigasawa H, Kobayashi R, Kikuta A, et al. Outcome of 154 patients with severe aplastic anemia who received transplants from unrelated donors: the Japan Marrow Donor Program. Blood. 2002;100:799-803.

15. Stern M, Passweg JR, Locasciulli A, Socie G, Schrezenmeier H, Bekassy $A N$, et al. Influence of donor/recipient sex matching on outcome of allogeneic hematopoietic stem cell transplantation for aplastic anemia. Transplantation. 2006;82:218-26.

16. Arai $Y$, Kondo T, Yamazaki H, Takenaka K, Sugita J, Kobayashi T, et al. Allogeneic unrelated bone marrow transplantation from older donors results in worse prognosis in recipients with aplastic anemia. Haematologica. 2016;101:644-52.

17. Huo M-R, Xu L-P, Li D, Liu D-H, Liu K-Y, Chen $H$, et al. The effect of HLA disparity on clinical outcome after HLA-haploidentical blood and marrow transplantation. Clin Transplant. 2012;26:284-91.

18. Lu D-P, Dong L, Wu T, Huang X-J, Zhang M-J, Han W, et al. Conditioning including antithymocyte globulin followed by unmanipulated HLA-mismatched/haploidentical blood and marrow transplantation can achieve comparable outcomes with HLA-identical sibling transplantation. Blood. 2006;107:3065-73.

19. Xiao-Jun H, Lan-Ping X, Kai-Yan L, Dai-Hong L, Huan C, Wei H, et al. HLA-mismatched/haploidentical hematopoietic stem cell transplantation without in vitro T cell depletion for chronic myeloid 
leukemia: improved outcomes in patients in accelerated phase and blast crisis phase. Ann Med. 2008:40:444-55.

20. Ozdemir ZN, Civriz Bozdag S. Graft failure after allogeneic hematopoietic stem cell transplantation. Transfus Apher Sci. 2018;57:163-7.

21. Yagasaki H, Takahashi Y, Hama A, Kudo K, Nishio N, Muramatsu H, et al. Comparison of matched-sibling donor BMT and unrelated donor BMT in children and adolescent with acquired severe aplastic anemia. Bone Marrow Transpl. 2010;45:1508-13.

22. Choi YB, Yi ES, Lee JW, Sung KW, Koo HH, Yoo KH. Immunosuppressive therapy versus alternative donor hematopoietic stem cell transplantation for children with severe aplastic anemia who lack an HLA-matched familial donor. Bone Marrow Transpl. 2017;52:47-52.

23. Holtan SG, DeFor TE, Lazaryan A, Bejanyan N, Arora M, Brunstein CG, et al. Composite end point of graft-versus-host disease-free, relapse-free survival after allogeneic hematopoietic cell transplantation. Blood. 2015;125:1333-8.

24. Przepiorka D, Weisdorf $D$, Martin $P$, Klingemann HG, Beatty $P$, Hows J, et al. 1994 Consensus Conference on Acute GVHD Grading. Bone Marrow Transpl. 1995;15:825-8.

25. Sullivan KM, Shulman HM, Storb R, Weiden PL, Witherspoon RP, McDonald $G B$, et al. Chronic graft-versus-host disease in 52 patients: adverse natural course and successful treatment with combination immunosuppression Blood. 1981;57:267-76.

26. Luznik L, O'Donnell PV, Fuchs EJ. Post-transplantation cyclophosphamide for tolerance induction in HLA-haploidentical bone marrow transplantation. Semin Oncol. 2012;39:683-93.

27. Mayumi H, Umesue M, Nomoto K. Cyclophosphamide-induced immunological tolerance: an overview. Immunobiology. 1996;195:129-39.

28. Iwasaki T. Recent advances in the treatment of graft-versus-host disease. Clin Med Res. 2004;2:243-52

29. Xu LP, Liu KY, Liu DH, Han W, Chen H, Chen YH, et al. A novel protocol for haploidentical hematopoietic SCT without in vitro T-cell depletion in the treatment of severe acquired aplastic anemia. Bone Marrow Transpl. 2012; 47:1507-12.

30. Chang YJ, Xu LP, Wang Y, Zhang XH, Chen $H$, Chen YH, et al. Controlled, randomized, open-label trial of risk-stratified corticosteroid prevention of acute graft-versus-host disease after haploidentical transplantation. J Clin Oncol. 2016;34:1855-63.

31. Ludajic K, Balavarca Y, Bickeboller H, Rosenmayr A, Fischer GF, Fae I, et al. Minor ABO-mismatches are risk factors for acute graft-versus-host disease in hematopoietic stem cell transplant patients. Biol Blood Marrow Transpl. 2009;15:1400-6.

32. Ozkurt ZN, Yegin ZA, Yenicesu I, Aki SZ, Yagci M, Sucak GT. Impact of ABOincompatible donor on early and late outcome of hematopoietic stem cell transplantation. Transpl Proc. 2009:41:3851-8.

33. Kimura F, Sato K, Kobayashi S, Ikeda T, Sao H, Okamoto S, et al. Impact of ABO-blood group incompatibility on the outcome of recipients of bone marrow transplants from unrelated donors in the Japan Marrow Donor Program. Haematologica. 2008;93:1686-93.

34. Damodar S, Shanley R, MacMillan M, Ustun C, Weisdorf D. Donor-torecipient $A B O$ mismatch does not impact outcomes of allogeneic hematopoietic cell transplantation regardless of graft source. Biol Blood Marrow Transpl. 2017;23:795-804.

35. Canals C, Muniz-Diaz E, Martinez C, Martino R, Moreno I, Ramos A, et al. Impact of ABO incompatibility on allogeneic peripheral blood progenitor cell transplantation after reduced intensity conditioning. Transfusion (Paris). 2004;44:1603-11.

36. Canaani J, Savani BN, Labopin M, Michallet M, Craddock C, Socie G, et al. ABO incompatibility in mismatched unrelated donor allogeneic hematopoietic cell transplantation for acute myeloid leukemia: a report from the acute leukemia working party of the EBMT. Am J Hematol. 2017;92:789-96.

37. Cao L-Q, Liu L, Xu L-P, Zhang X-H, Wang Y, Fan Q-Z, et al. Correlation between pediatric donor characteristics and cell compositions in mixture allografts of combined G-CSF-mobilized PBSCS and bone marrow allografts. Bone Marrow Transplant. 2018:53:108-10.

38. Wang Y-T, Zhao X-Y, Zhao X-S, Xu L-P, Zhang X-H, Wang Y, et al. The impact of donor characteristics on the immune cell composition of mixture allografts of granulocyte-colony-stimulating factor-mobilized marrow harvests and peripheral blood harvests. Transfusion (Paris). 2015;55:2874-81.

39. Vasu S, Leitman SF, Tisdale JF, Hsieh MM, Childs RW, Barrett AJ, et al. Donor demographic and laboratory predictors of allogeneic peripheral blood stem cell mobilization in an ethnically diverse population. Blood. 2008;112:2092-100.
40. Chen J, Burns KM, Babic A, Carrum G, Kennedy M, Segura FJ, et al. Donor body mass index is an important factor that affects peripheral blood progenitor cell yield in healthy donors after mobilization with granulocytecolony-stimulating factor. Transfusion (Paris). 2014;54:203-10.

41. Kim HT, Zhang MJ, Woolfrey AE, St Martin A, Chen J, Saber W, et al. Donor and recipient sex in allogeneic stem cell transplantation: what really matters. Haematologica. 2016;101:1260-6.

42. Randolph SS, Gooley TA, Warren EH, Appelbaum FR, Riddell SR. Female donors contribute to a selective graft-versus-leukemia effect in male recipients of HLA-matched, related hematopoietic stem cell transplants. Blood. 2004;103:347-52.

\section{Publisher's Note}

Springer Nature remains neutral with regard to jurisdictional claims in published maps and institutional affiliations.
Ready to submit your research? Choose BMC and benefit from:

- fast, convenient online submission

- thorough peer review by experienced researchers in your field

- rapid publication on acceptance

- support for research data, including large and complex data types

- gold Open Access which fosters wider collaboration and increased citations

- maximum visibility for your research: over $100 \mathrm{M}$ website views per year

At $\mathrm{BMC}$, research is always in progress.

Learn more biomedcentral.com/submissions 